\title{
Assessing and accessing the small airways; implications for asthma management
}

\author{
Nicola Scichilone ${ }^{\mathrm{a}, *}$, Marco Contoli ${ }^{\mathrm{b}}$, Davide Paleari ${ }^{\mathrm{c}}$, Pietro Pirina ${ }^{\mathrm{d}}$, Andrea Rossi ${ }^{\mathrm{e}}$, \\ Claudio Maria Sanguinetti ${ }^{\mathrm{f}}$, Pierachille Santus ${ }^{\mathrm{g}}$, Matteo Sofia ${ }^{\mathrm{h}}$, Nicola Sverzellati ${ }^{\mathrm{i}}$ \\ ${ }^{a}$ Biomedical Department of Internal and Specialist Medicine (DIBIMIS), Section of Pneumology, University of Palermo, via Trabucco 180, 90146 Palermo, Italy \\ ${ }^{\mathrm{b}}$ Section of Respiratory Diseases, University of Ferrara, Via Savonarola 9, 44121 Ferrara, Italy \\ ${ }^{\mathrm{c}}$ Medical Department, Chiesi Farmaceutici S.p.A., via Palermo 26/A, 43122, Parma, Italy \\ d UOC di Pneumologia, AOU di Sassari, Viale San Pietro, 07100 Sassari, Italy \\ e UOC Pneumologia, AOUI, Ospedale Maggiore di Borgo Trento, Piazzale Stefani 1, 37126 Verona, Italy \\ ${ }^{\mathrm{f}}$ Quisisana Clinical Center, Via Catone 29, 00192 Roma, Italy

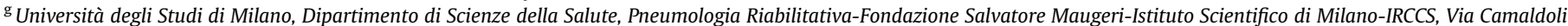 \\ 64, 20138 Milano, Italy \\ ${ }^{\text {h }}$ Clinica Pneumologica Federico II Ospedale Monaldi, Via L. Bianchi, 80131 Napoli, Italy \\ ${ }^{\mathrm{i}}$ Scienze Radiologiche, Padiglione Barbieri, Azienda Ospedaliero-Universitaria di Parma, 43100 Parma, Italy
}

\section{A R T I C L E I N F O}

\section{Article history:}

Received 8 May 2012

Received in revised form

1 October 2012

Accepted 6 October 2012

Keywords:

Asthma

Peripheral airways

Small airways

Inflammation

Imaging

Extrafine

\begin{abstract}
A B S T R A C T
Despite the wealth of experience in the management of asthma, the disease remains inadequately controlled in some patients, who face long-term respiratory impairment and disability. The disease has been characterised as an inflammatory condition affecting first the larger airways and eventually the smaller airways, but there is evidence that peripheral airway involvement defines a particular and more severe phenotype of asthma. For this reason, assessing functional and biological parameters reflective of small airways involvement is important prognostically. No assessment method is universally and directly representative of peripheral airway function, but the traditional spirometric tests, including vital capacity, residual volume and forced vital capacity, are somewhat correlated with this function; useful methods for further assessment include the single-breath nitrogen wash-out test, impulse oscillometry, nitrous oxide and exhaled breath concentrate measurements, as well as computed tomography to reflect air trapping and response to treatment. Formulation advancements have made for easier treatment access to the smaller airways, with the new extrafine formulations resulting in better asthma control compared with non-extrafine formulations.
\end{abstract}

(c) 2012 Elsevier Ltd. All rights reserved.

\section{The role of small airways in asthma: old concepts and new challenges}

The prevalence of asthma, which affects up to $10 \%$ of adults and $35 \%$ of children, is increasing worldwide [1,2]. The disease remains inadequately controlled on currently available therapies in a large proportion of patients [3], despite a deeper understanding and growing knowledge of the pathology, and attention and adherence to detailed treatment guidelines [4]. The consequences of this

\footnotetext{
* Corresponding author. Tel.: +39 091 6802655; fax: +39 0916882842.

E-mail addresses: nicola.scichilone@unipa.it, scichilone@yahoo.com (N. Scichilone), ctm@unife.it (M. Contoli), d.paleari@chiesi.com (D. Paleari), pirina@uniss.it (P. Pirina), andrea.rossi2@ospedaleuniverona.it (A. Rossi) c.sanguinetti@alice.it (C.M. Sanguinetti), pierachille.santus@unimi.it (P. Santus) matteo.sofia@unina.it (M. Sofia),nicola.sverzellati@unipr.it (N. Sverzellati).
}

inadequate control of the disease are long-term respiratory impairment and disability $[2,5,6]$.

The role of the peripheral airways in asthma is increasingly being recognized as a relevant target (Fig. 1) for asthma treatment $[7,8]$. The contribution of small airways to the pathophysiology of asthma, combined with the presence of the relevant receptors in these airways, suggests that this site should not be neglected in the monitoring of asthma or in the development of treatments for the disease [9]. Asthma is a chronic inflammatory disease of the airways including the most peripheral ones. There is abundant evidence that inflammatory and functional abnormalities of the lung periphery occur in all stages of the disease from the mildest $[10,11]$ to the most severe form [12,13]. Interestingly, a correlation between disease severity and the magnitude of small airway impairment has been documented [14]. The question arises as to whether peripheral airways are a site of structural and functional alterations in asthma irrespective of the clinical manifestation or 


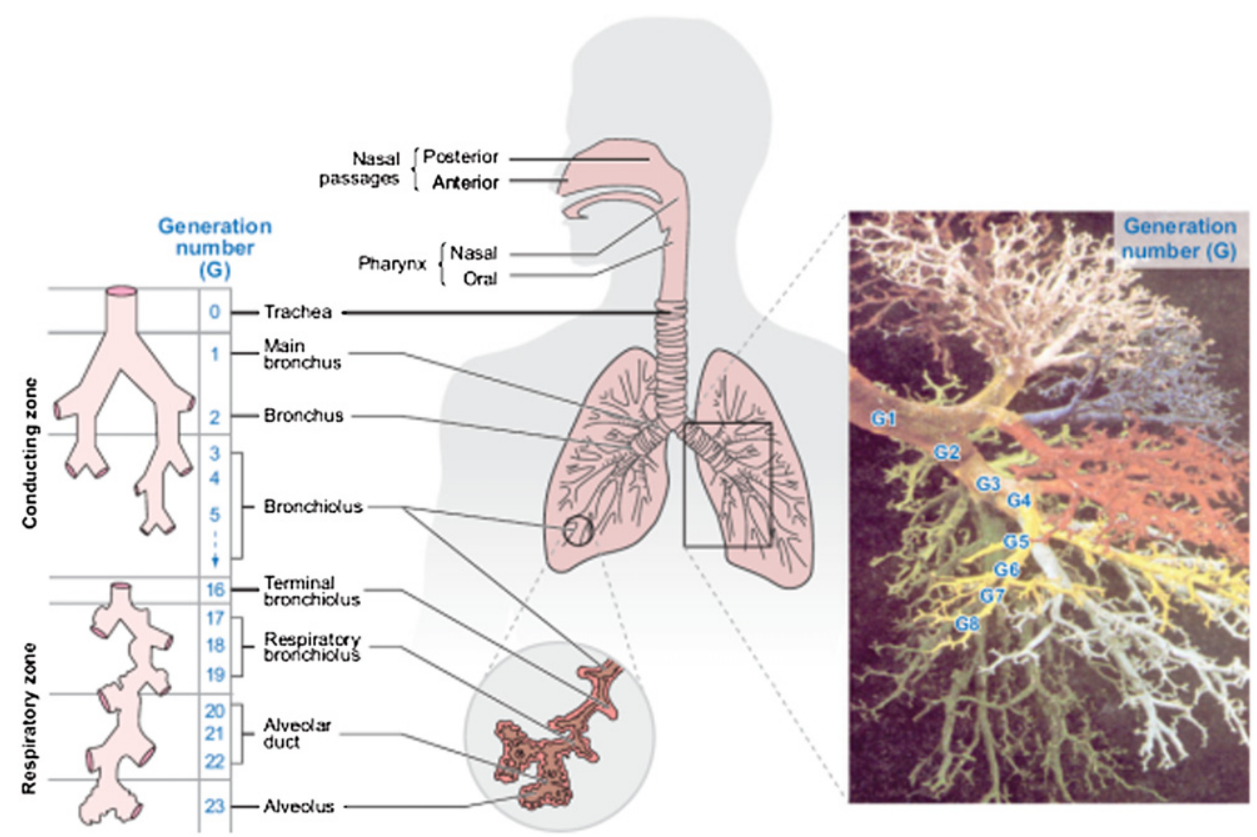

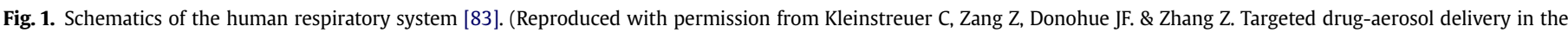
human respiratory system. Annu Rev Biomed Eng. 2008; 10:195-220. published by Annual Reviews).

does the involvement of the peripheral airways in asthma represent a specific phenotype of the disease that leads to more severe manifestations, poor clinical control and/or poor response to treatment. From a purely speculative perspective, the distinction carries pathophysiological implications: in the first case, the alterations of the peripheral airways do not describe the most important pathogenetic features of asthma but merely represent the consequence of the disease progression. On the other hand, if the pathophysiological changes of the peripheral airways are considered as defining a phenotype of asthma, it is logical to assume that, at least in this group of asthmatics, the peripheral airway involvement is a relevant pathogenetic mechanism. Specifically designed studies are needed to clarify the matter.

From a clinical standpoint, the identification of a specific asthma phenotype characterised by prevalent small airway impairment advocates the need for functional and biological tools that can accurately assess the peripheral area of the lung. Most importantly, assessing and accessing the peripheral airways becomes mandatory when the small airway involvement potentially carries prognostic implications. From this perspective, the identification of: i) asthma phenotypes characterised by enhanced small airway impairment and, ii) the link between poor control/asthma severity and small airway abnormalities, raises the question whether pharmacological approaches able to increase drug deposition within the airways will result in further clinical benefit in these patients.

In the field of asthma, the concept of "future risk" is gaining increasing importance in the management of the disease, as emphasized by recent guidelines [2]. Whether the detection of small-airway abnormalities indicates those patients at major risk of asthma attacks or more severe disease, or predicts those likely to benefit from a specific intervention, is unknown and should be pursued in future studies.

The following sections will discuss the pathology of peripheral airways in asthma, methods of assessment of the peripheral airways function, and formulation advancements for better drug delivery throughout the airways.

\section{Peripheral airways pathology: the strength of evidence}

Evidence accumulating in recent decades indicates that inflammatory changes of the proximal airways of asthmatics also occur in the distal airways [15]. The assessment of the distal tract of the bronchial tree has always been a difficult task due to its relative inaccessibility. However, with the improvement of bronchoscopic, morphometric and immunohistochemical techniques, a better evaluation of airways less than $2 \mathrm{~mm}$ in diameter has been made possible [16]. It is now accepted that inflammation is present throughout the bronchial tree of asthmatics; this inflammatory process is characterized by the presence of activated $\mathrm{T}$ lymphocytes and activated eosinophils, increased mucus plugging obstructing the lumen, and smooth muscle hyperplasia [17]. In a study designed to evaluate the inflammatory changes of large and small airways on lung tissue obtained from surgical resections of asthmatic subjects, the number of activated eosinophils was significantly greater in the distal portion of the airways and in the context of the alveolar walls $[11,18]$.

Additional studies performed in asthmatics confirmed that the inflammatory changes to the peripheral airways parallel the severity of the disease. In a study by Carroll et al. [19], the increased expression of mast cell chymase in the outer area of the distal airways was significantly associated with impaired lung function in individuals with severe asthma. In subjects with severe asthma compared with those with mild to moderate asthma, an increased production of alveolar nitric oxide (NO), but not bronchial NO, was also found [20], implying that a more intense degree of inflammation occurs in the periphery of the bronchial tree in the most severe forms of asthma.

In patients with severe or fatal asthma, there is increased thickness of the airway smooth muscle layer in the proximal and distal airways and increased smooth muscle cell size [21]. Recent findings suggest that parenchymal abnormalities may also affect airflow obstruction in asthmatics [13]. Indeed, a loss of alveolar attachments was demonstrated in association with a reduction in lung elastic recoil, leading to airway collapse. In patients with 
severe asthma, the progressive loss of lung function is caused by structural alterations and remodelling of the proximal and distal airways, and destruction of lung parenchyma [22].

Specific abnormalities of the distal airways and lung parenchyma have also been described in nocturnal asthma, which occurs in $30-75 \%$ of the asthmatic population [23]. In nocturnal asthma, but not in non-nocturnal asthma, a more pronounced inflammation in the peripheral airways rather than in the large central airways was described, with a significant increase in lymphocytes, macrophages and eosinophils during the night [24]. The percentage of eosinophils and macrophages was also significantly increased in the alveolar tissue and was related to a nocturnal reduction in lung function. The inflammatory response observed in the context of the alveolar tissue could explain the loss of airways-parenchyma coupling detected in individuals with nocturnal asthma [25].

\section{Assessing the peripheral airways: from the research perspective to clinical practise}

Methods of peripheral airways assessment include lung function tests, measurements of biomarkers, and imaging techniques. However, no universally accepted criteria for these tests have been proposed as being directly representative of peripheral airways involvement, and changes in these parameters have not yet been proven to affect the clinical outcomes of patients with asthma [7,8].

\subsection{Functional assessment of peripheral airways}

Commonly employed spirometric tests, such as forced expiratory volume in $1 \mathrm{~s}\left(\mathrm{FEV}_{1}\right)$ and the ratio of $\mathrm{FEV}_{1}$ to forced vital capacity $\left(\mathrm{FEV}_{1} / \mathrm{FVC}\right)$, generally reflect large airways function and loss of lung elastic recoil $[26,27]$. Measures of lung volumes, such as vital capacity (VC), residual volume (RV) and forced vital capacity (FVC) are, to some extent, correlated to the functional state of the peripheral airways. VC is reduced in patients with peripheral airways obstruction, and this reduction may occur before that of the $\mathrm{FEV}_{1} / \mathrm{VC}$ ratio [26]. $\mathrm{RV}$ is increased in patients with air trapping, a phenomenon that is secondary to alterations that mainly occur at the level of peripheral airways [7]. FVC is reduced at any level of airway obstruction, but may be also a reflection of air trapping [7]. In the late nineties, spirometric pattern characterized by a decrease in VC and $\mathrm{FEV}_{1}$, an increase in RV and RV/total lung capacity (TLC), and normal TLC and $\mathrm{FEV}_{1} / \mathrm{FVC}$ was described by Stănescu [28]. Since an increase in RV and RV/TLC represents a marker of hyperinflation and air trapping, this pattern has been proposed as an early detector of peripheral airways disease $[29,30]$. This alteration has been observed in the early stages of emphysema, elderly people and asymptomatic asthma [29,30]. Although the measurement of RV is an easy-to-perform test, with good reproducibility and low intrapatient variability, it is commonly envisaged as a rough method of estimating the function of small airways, mainly because it only allows a volumetric characterization of premature airway closure and air trapping, and is not able to detect less evident functional changes of distal airways conductance and ventilation patterns.

Other spirometric tests are under investigation for the assessment of peripheral airways function. The mean forced expiratory flow (FEF) between $25 \%$ and $75 \%$ of FVC $\left(\mathrm{FEF}_{25-75}\right)$ is one of the most popular indices of peripheral airways obstruction, resembling the concavity of the flow-volume curve [31]. However, its use in clinical practise is limited by physiological variability and measurement inconsistency issues [32]. Its value as a predictor of peripheral obstruction has also been questioned following findings from the Severe Asthma Research Program of the National Heart Lung and Blood Institute, which showed a lack of correlation between $\mathrm{FEF}_{25-75}$ and other indices of air trapping [32].
Among the non-invasive techniques that are proposed to evaluate small airways function, the forced oscillation technique (FOT) is gaining increasing importance. FOT uses the non-invasive superimposition of pressure fluctuations on the airway over the subject's tidal breathing. FOT was first described by DuBios in 1956 as a method to characterize respiratory impedance [33]. Similar to FOT, impulse oscillometry (IOS) is easy to perform and requires only passive patient cooperation [34]. IOS delivers a regular square wave of pressure 5 times per second, and has the advantage of generating a larger sample during measurements thereby emitting a continuous spectrum of frequencies that provide a more detailed characterization of respiratory mechanics [35]. IOS has been employed in adults as well as in preschool asthmatic children to identify lung dysfunction $[34,36]$ and in the clinical diagnostic testing of individuals with airway hyperreactivity and airway obstruction. IOS could also be used during bronchoprovocation challenges. The advantage of continuous spectra could be important in conditions of regional non-homogeneities.

A recent paper from Takeda et al. [37] reported that parameters obtained by IOS are strongly correlated with clinical symptoms and asthma control in asthmatics. Peripheral and proximal airway functions, as assessed separately by IOS, independently contribute to health status, dyspnoea and disease control. IOS also appears to be a sensitive screening tool for the early detection of bronchial obstruction [38]. More recently, Oppenheimer et al. proposed that IOS can be used as a non-invasive tool for assessment of distal airway function when spirometry is normal [39], and can be applied to various clinical settings including early diagnosis of COPD and asthma in clinical remission and occupational/environmental irritant exposure.

The single-breath nitrogen $\left(\mathrm{sbN}_{2}\right)$ washout test is another noninvasive tool to assess small airways dysfunction and ventilation inhomogeneity, and has been used since the 1960s to detect early closure of peripheral airways. It is based on the detection of regional differences in ventilation distribution, represented by the phase III slope of the flow-volume curve following the washout test. Towards the end of expiration, an abrupt increase in $\mathrm{N}_{2}$ concentration is observed, which corresponds to the beginning of phase IV. This is due to the preferential emptying of the apex, following closure of airways at the base of the lung. The volume at which phase IV begins is termed closing volume, and reflects small airways abnormalities. Despite being an easily performed and sensible technique [40], it suffered from poor reproducibility and predictability in the past [41]. This is no longer a limitation; $\mathrm{sbN}_{2}$ has been employed in studies specifically addressing the relationship between asthma severity and small airways dysfunction [42].

The multiple breath nitrogen washout (MBW) test measures functional residual capacity (FRC). Patients with high airways resistance take longer to clear the nitrogen, and the test can distinguish between obstructions in the large or small airways. Dutrieue et al. [43] and Verbanck et al. [44] used the MBW test to derive the two variables, Scond (index of conductive ventilation heterogeneity) and Sacin (index of acinar ventilation heterogeneity). In asthmatic subjects, the clinical application of MBW includes evaluation of ventilation heterogeneity after an airway challenge, and analysis of response differences to inhaled steroids when comparing non-extrafine and extrafine particles $[45,46]$.

The influence of ageing on the ventilation heterogeneity needs to be taken into consideration. In this scenario, Verbanck and colleagues recently found that, with respect to the clinical response, age has a small but consistent effect that needs to be factored in when using the MBW indices for the detection of small airways abnormality in disease [47].

The oesophageal balloon technique represents the gold standard for the measurement of changes in pleural pressure, and is one of the most reliable methods to disclose the premature closure of 
small airways [48]. Through the reading of the quasi static pressure volume curve, and its departure from the exponential curve, the volume at which closure of the most peripheral airways occurs is recorded. It is a rather uncomfortable procedure, which cannot be proposed, in daily clinical practise. With regard to the assessment of the lung periphery, the oesophageal balloon technique allows measurement of dynamic compliance. As opposed to static compliance, which is measured at points of no flow, dynamic compliance is measured during airflow. While in healthy subjects, dynamic and static compliance are equal, in chronic obstructive diseases, the ratio between the two decreases as the breathing frequency rises. This is due to the effect of uneven time constants on ventilation. The lung compartments with obstructed airways, and therefore long time constants, continue to fill while the rest of the lung has begun to exhale. The asynchronous behaviour of different areas of the lung implies a frequency dependence of compliance determined by their different time constants. As the breathing pattern increases, the dynamic compliance falls. This asynchronous behaviour of lung units has been ascribed primarily to obstruction in the small airways. Indeed, increased resistance of peripheral airways is responsible for uneven time constants and, therefore, for the change in dynamic compliance with breathing frequency [49-51].

\subsection{Biological assessment of peripheral airways}

Fractional exhaled nitric oxide (FeNO) is a non-invasive measure of airways inflammation. By monitoring the expiratory flow, it is possible to differentiate selectively between NO from the conducting airways and that coming from the respiratory zone (alveolar NO). The detection of alveolar NO is associated with nocturnal asthma, symptomatic asthmatics and asthmatics with more severe disease [8,52]. Moreover, alveolar NO is more sensitive to oral than to inhaled corticosteroids, suggesting that it may represent true abnormalities of peripheral airways, which are better reached by systemic drugs than by conventional inhaled formulations [20]. More recently, a method of monitoring the daily fluctuations in FeNO values with quantification over a period of time has been established, providing information on a subject's asthma severity with regard to asthma control and exacerbation risk [53].

Exhaled breath condensate (EBC) obtained by the cooling of the exhaled breath contains evaporated and condensed components plus some droplets from the airway lining fluid, but EBC markers of oxidative stress such as hydrogen peroxide, isoprostanes, nitrogen oxides, $\mathrm{pH}$, ammonia, prostanoids and leukotrienes are abnormal in bronchial asthma [54]. Remarkably, both FeNO and 8-isoprostane concentrations in EBC were positively correlated with small airways function in asthmatics [55]. However, it is unlikely that one single marker might be representative of small airways involvement in asthma. EBC is a suitable matrix for metabonomic studies, which involve measurements of the dynamic multiparametric metabolic response of living systems to pathophysiological stimuli or genetic modification. The method includes reference analytical techniques such as mass spectrometry or nuclear magnetic resonance spectroscopy (NMR) [56]. By applying this approach, NMRbased metabonomic analyses of EBC clearly discriminated between asthmatic and healthy children, with a $95 \%$ success rate in their classification [57]. Whether a metabonomic study of EBC could reveal a distinct profile of small airways disease in asthma is currently unknown.

\subsection{Imaging assessment of peripheral airways}

Computed tomography (CT) has emerged as a useful tool to assess peripheral airways disease noninvasively in patients with asthma. The cardinal CT sign of peripheral airways disease in asthma is the presence of pulmonary decreased attenuation areas, which are more conspicuous and extensive on expiratory CT scans [58-60]. They reflect air trapping, which may be either secondary to transient small airway obstruction or spasm or caused by fixed peripheral remodelling [61-63]. There are two systems for quantifying air trapping on CT: the visual score and the densitometric analysis. The major disadvantage of a subjective approach is the variation between observers, and the densitometric analysis, despite its limitations, has been the technique of choice in recent scientific investigations and pharmaceutical trials. Specifically, either mean lung density or -850 HU cut-off CT density has been used to quantify air trapping in asthmatic subjects $[63,64]$.

Quantification of air trapping in expiratory studies may provide additional information regarding response to therapy targeted for small airways disease that is not readily captured by physiologic measures $[62,65]$. This technique was used to compare the relative efficacy of two different inhaled medications on small airway hyper-reactivity; small-size inhaled particles prompted a significant improvement in air trapping compared with traditional-size particles $[62,65]$. These studies demonstrate the potential use of quantitative imaging in asthmatic patients as a surrogate end point for small airways remodelling in response to therapies.

Air trapping quantification has also been used to define asthmatic phenotypes. A recent study by Busacker and colleagues showed that quantitative CT can identify a group of individuals with a high risk of severe disease [64]. Individuals in the group with air trapping above the median level were significantly more likely to have a history of asthma-related hospitalizations, intensive care unit visits and/or mechanical ventilation [64].

CT imaging of pulmonary ventilation patterns in patients with asthma has evolved over the last decade with the introduction of more sophisticated techniques. Although the direct assessment of peripheral remodelling by CT measurements is still limited, due to the difficulty in accurately measuring the distal small airways (typically $<2 \mathrm{~mm}$ diameter), computer-assisted 3-dimensional analysis of the airway tree structure is currently advancing the evaluation of the small airways disease (Fig. 2a and b). By using this technique in asthmatic patients, it has been shown that the strongest correlation with airflow obstruction was found through airway wall measurements of the more distal airways [66]. Although current evidence indicates that small airways obstruction could be routinely assessed using CT scanning, this technique does have some limitations, including lack of standardization of the technical parameters of the CT scanner, lack of consensus on the best index for small-airways disease assessment, and exposure of subjects to ionizing radiation. Indeed, the regular assessment of small airway disease via CT imaging is still not part of routine clinical practise for young asthmatic patients.

In conclusion, clinical trials have demonstrated that several methodologies are currently available to assess specifically the peripheral airways, and to investigate the presence of structural and functional changes in this bronchial area. These methodologies differ, however, in terms of accuracy, reliability, accessibility and cost, and their validation in real-life studies is lacking. From a clinical approach, individualized choices should be made based on the specific need and resources available. We propose an algorithm that takes into account the criteria described above: when assessing peripheral airways in daily practise, parameters of the flowvolume spirometric curve, such as the $\mathrm{FEF}_{25-75}$, are easily accessible to general practitioners. If peripheral airway involvement is suspected, referral to a pulmonologist is recommended for a complete lung function evaluation, including the $\mathrm{sbN}_{2}$ washout test; IOS may also be useful as an alternative lung function test. Measurement of alveolar NO, which should always be accessible, 
a
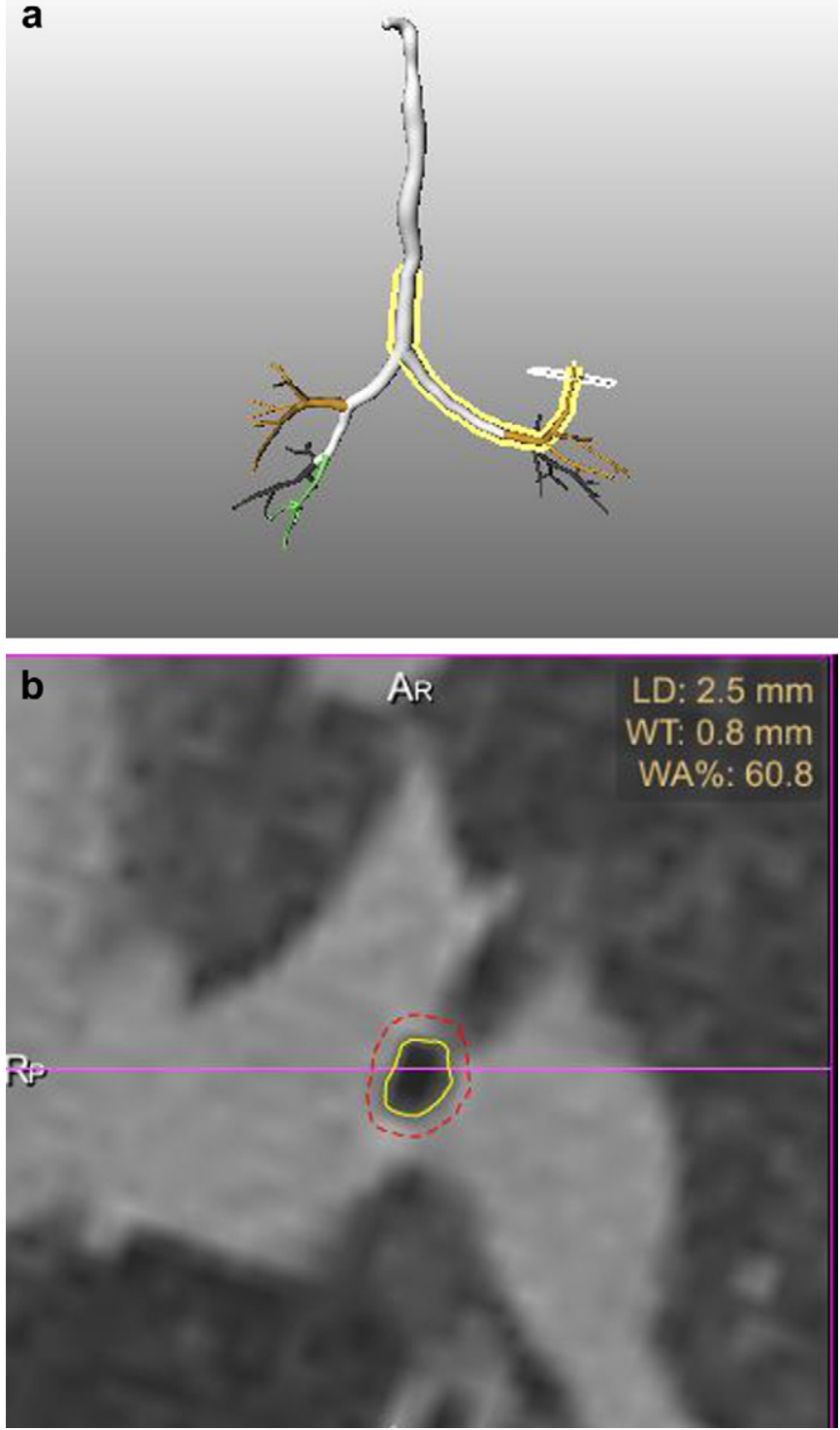

Fig. 2. Quantitative analysis of airway lumen and wall area in a young patient with severe asthma. (a) Multidetector CT permits reconstruction of airway tree using proprietary software (MEVIS Airway Examiner) which automatically provides bronchial measurements for selected pathways. (b) Orthogonal image through the airway provides measurement of airway dimensions. The airways are moderately thickwalled. (Courtesy of Michael Schmidt, Fraunhofer MEVIS, Bremen, Germany).

facilitates the definition of future risk and the optimal choice of treatment, and predicts potential benefits. Imaging assessment is advocated in patients with severe or difficult-to-control asthma.

\section{Accessing the peripheral airways: current evidence and future approaches}

Despite the evidence supporting the contribution of peripheral airways to asthma pathophysiology and clinical manifestations, very few studies have been designed to address specifically the importance of treating the distal part of the lung. Following the outlawing of chlorofluorocarbons (CFC) for environmental reasons, the development of the new hydrofluoroalkane (HFA) inhaler propellant also enabled the development of extrafine particle size inhaled drug formulations, which means treatment can reach the peripheral airways. The use of an HFA propellant is necessary, but it is not the only prerequisite for extrafine particle formulations. Indeed, most HFA pressured metered dose inhalers (pMDIs) on the market have similar characteristics to the corresponding CFC pMDIs [67]. To date, there are some single-agent extrafine formulations on the market (beclometasone, ciclesonide, formoterol), and only one combination product available (beclometasone/formoterol) [68]. Extrafine solution pMDIs can deliver compounds with a mass median aerodynamic diameter that is smaller than that delivered by other available devices [69]. Thus, these devices are able to deliver particles to both large and small airways, resulting in a significant increase in peripheral airways drug deposition with respect to the delivered dose [70].

Initial studies evaluating the efficacy of extrafine formulations in asthmatic patients were performed with inhaled corticosteroids (ICS) alone. These studies revealed that ICS extrafine formulations were superior to non-extrafine formulations in modulating functional and inflammatory parameters, reflecting small airway abnormalities $[45,62,71]$. The relative superiority of extrafine formulations was also observed for clinical outcomes that are not directly linked to small airways. Indeed, it was calculated that 2.6-fold non-extrafine beclometasone (BDP) is required to achieve the same improvement in $\mathrm{FEV}_{1}$ as extra-fine HFA-BDP [72]. Moreover, in an open-label, 12-month randomised controlled trial, Juniper et al. showed that in asthmatic patients previously treated with non-extrafine $\mathrm{CFC}-\mathrm{BDP}$ and switching to equipotent doses of extra-fine HFA-BDP (half of the dose of non-extra-fine CFC-BDP), there was a significant improvement in asthma quality of life compared with those patients who continued to receive nonextrafine CFC-BDP [73].

More recent studies were conducted using a fixed combination of extrafine beclometasone/formoterol (BDP/F). Huchon et al. showed that extrafine BDP/F delivered by an HFA pMDI (400/ $24 \mathrm{mcg}$ ) was superior in improving asthma control over 24 weeks of treatment to the combination of the same drugs formulated as larger non-extrafine agents, at equipotent doses $(1000 \mathrm{mcg}$ BDP $+24<\operatorname{mcg}$ F) [74]. Moreover, in two large studies $(>200$ patients in each study), Papi and co-workers $[75,76]$ reported that the extrafine combination of $\mathrm{BDP} / \mathrm{F}$ was comparable in terms of lung function improvement (as measured by morning peak expiratory flow changes) to the non-extrafine combinations of an ICS with a long-acting $\beta 2$ agonist (LABA), budesonide/formoterol $(\mathrm{BUD} / \mathrm{F})$ and fluticasone/salmeterol (FP/S), at equipotent doses.

Achieving and maintaining asthma control is a major goal of asthma care. A real life observational study was conducted by Müller et al. to compare the asthma control efficacy of a BDP/F pMDI extrafine formulation vs BUD/F and $\mathrm{FP} / \mathrm{S}$ combinations (non-extrafine formulations, both delivered as dry powder inhalers [DPIs]). In this real life setting, the proportion of patients achieving asthma control was significantly higher in the BDP/F extrafine group than in the non-extrafine BUD/F or FP/S group, and this was achieved with a significantly lower ICS mean daily dose [77]. This was confirmed in a recently published large observational study, showing that the extrafine BDP/F combination resulted in better asthma control and quality of life compared to non-extrafine formulations [78]. However, it remains to be established whether the addictive effect of extrafine formulations compared to no extrafine formulations on asthma control is related to the small airways targeting or whether may represent a consequence of a better distribution of the delivered drugs throughout the bronchial tree.

When functional parameters more related to peripheral airways abnormalities were considered, 12 weeks of extrafine $\mathrm{BDP} / \mathrm{F}$ combination treatment was significantly superior to an equipotent dose of the non-extrafine $\mathrm{FP} / \mathrm{S}$ combination in improving air trapping (without increased risk of systemic effects), which was measured by a reduction in FVC [75]. In addition, 12 weeks of 
extrafine $\mathrm{BDP} / \mathrm{F}$ combination treatment tended to be significantly superior to equipotent doses of non-extrafine $\mathrm{FP} / \mathrm{S}$ in improving closing capacity measured by the $\mathrm{sbN}_{2}$ washout test [79]. These latter results provide direct evidence of the superiority of the extrafine ICS/LABA combinations compared to the non-extrafine combinations in improving small-airways function, possibly linked to the higher proportion of small particle delivered by extrafine formulations able to reach the more peripheral airway tract [80]. However, non-extrafine formulations are also able to significantly modify functional parameters reflecting small airways dysfunctions [81]. This finding is in line with the fact that also nonextrafine formulations can deliver a proportion of small particle able to reach the periphery of the lung. Thus, despite the evidence that extrafine formulations are more potent as compared to non extrafine formulations in targeting peripheral airways (peripheral deposition of the BDP/F extrafine combination is 2.55 fold higher compared to the $\mathrm{FP} / \mathrm{S}$ non-extrafine combination) $[80,82]$, the relative contribution of the modulation of peripheral airway abnormalities on clinical outcomes is still unclear. Head to head (extrafine vs non-extrafine) randomized controlled studies are needed to evaluate whether changes in small-airway abnormalities correlate with improvement in clinical outcomes. Similarly, and even more importantly, clinical trials are needed to evaluate whether extrafine formulations would represent a specific therapeutic option for specific groups of patients characterised by enhanced small airway dysfunctions.

\section{Conclusions}

Evidence of substantial and severe inflammation in the peripheral airways of patients with asthma has highlighted the importance of the assessment and treatment of this airway compartment. Moreover, several studies document better correlations between inflammatory, functional and imaging parameters reflecting small airway and both asthma control scores and quality of life. Recent data, coming from real-life studies show that extrafine formulations result in better asthma control compared to non-extrafine formulations. Whether this achievement is the result of the broader distribution of the delivered compounds through the airways or whether it is due to specific targeting of small airway dysfunction is still largely unknown, and appropriately designed studies are warranted. Relative inaccessibility of the peripheral airways and inadequacy of routine diagnostic methods to explore the more peripheral airway compartments has limited both the clinical research on small airways and the clinical assessment of small airways in daily clinical practise. However, in particular when managing cases of difficult-to-treat/uncontrolled asthma, we propose that physicians perform lung function assessments to classify the severity of asthma, and assess peripheral airway function and inflammation to detect the involvement of this site, in order to evaluate the possibility of individualized therapeutic decisions. It is no longer acceptable to define the peripheral airways as the "silent zone" and to forget their crucial function in respiratory system. The "silent zone" speaks loudly, but only if we listen carefully.

\section{Acknowledgements}

NS has received financial support for research and for congress attendance from Boehringer Ingelheim, Novartis and Chiesi Farmaceutici.

MC has received sponsorship from Chiesi Farmaceutici, Glaxo Smith Kline, Menarini and Novartis.

PP has received financial support for research and for congress attendance from Novartis, Glaxo Smith Kline, Chiesi Farmaceutici, Menarini, and Pfizer.
AR has received financial support for research and for congress attendance from Glaxo Smith Kline, Pfizer, Boehringer Ingelheim, Novartis, Chiesi Farmaceutici, and AstraZeneca.

PS has received financial support for research and for congress attendance from Glaxo Smith Kline, Pfizer, Boehringer Ingelheim, Novartis, Chiesi Farmaceutici, AstraZeneca, Zambon, Menarini, and Abbott.

MS has received financial support for research and for congress attendance from Glaxo Smith Kline, Pfizer, Boehringer Ingelheim, Novartis, Chiesi Farmaceutici, AstraZeneca, Actelion, and Rottapharm.

DP is an employee of Chiesi Farmaceutici S.p.A., Parma, Italy.

CMS and NS have no conflicts of interest to declare.

Editorial assistance was provided by Denis Bilotta on behalf of inScience Communications, Springer Healthcare. This assistance was sponsored by Chiesi Farmaceutici.

\section{References}

[1] Aubier M, Neukirch F, Annesi-Maesano I. Epidemiology of asthma and allergies. The prevalence of allergies increases worldwide, and asthma has reached his highest-ever prevalence in Europe: why? Bull Acad Natl Med 2005;189(7): 1419-34. discussion 1434.

[2] Global Initiative for Asthma (GINA). Global strategy for asthma management and prevention [online]. Available from URL: http://www.ginasthma.com; 2011 [Accessed 19.11.10].

[3] Ulrik CS, Lange P. Targeting small airways in asthma: improvement in clinical benefit? Clin Respir J 2011;5(3):125-30.

[4] Martin RJ. Therapeutic significance of distal airway inflammation in asthma. J Allergy Clin Immunol 2002;109(Suppl.):S447-60.

[5] National Heart Blood and Lung Institute. National asthma education and prevention program. Expert Panel Report 3 (EPR3): guidelines for the diagnosis and management of asthma [online]. Available at: URL: http://www. nhlbi.nih.gov/guidelines/asthma/asthgdln.htm [Accessed 02.03.11]

[6] British Thoracic Society. British guideline on the management of asthma: a national clinical guideline (revised 2009) [online]. Available from URL: http//www.brit-thoracic.org.uk [Accessed 19.11.10].

[7] Contoli M, Bousquet J, Fabbri LM, Magnussen H, Rabe KF, Siafakas NM, et al. The small airways and distal lung compartment in asthma and COPD: a time for reappraisal. Allergy 2010;125:830-7.

[8] Scichilone N, Battaglia S, Olivieri D, Bellia V. The role of small airways in monitoring the response to asthma treatment: what is beyond FEV1? Allergy 2009;64(11):1563-9.

[9] Tulic MK, Christodoulopoulos P, Hamid Q. Small airway inflammation in asthma. Respir Res 2001;2:333-9.

[10] Carroll N, Cooke C, James A. The distribution of eosinophils and lymphocytes in the large and small airways of asthmatics. Eur Respir J 1997 Feb; 10(2):292-300.

[11] Hamid Q, Song Y, Kotsimbos TC, Minshall E, Bai TR, Hegele RG, et al. Inflammation of small airways in asthma. J Allergy Clin Immunol 1997; 100(1):44-51.

[12] Wenzel SE, Szefler SJ, Leung DY, Sloan SI, Rex MD, Martin RJ. Bronchoscopic evaluation of severe asthma. Persistent inflammation associated with high dose glucocorticoids. Am J Respir Crit Care Med 1997 Sep;156(3 Pt 1):737-43.

[13] Mauad T, Silva LF, Santos MA, Grinberg L, Bernardi FD, Martins MA, et al Abnormal alveolar attachments with decreased elastic fiber content in distal lung in fatal asthma. Am J Respir Crit Care Med 2004;170(8):857-62.

[14] Contoli M, Kraft M, Hamid Q, Bousquet J, Rabe KF, Fabbri LM, et al. Do small airway abnormalities characterize asthma phenotypes? In search of proof. Clin Exp Allergy 2012 Aug;42(8):1150-60.

[15] Kraft M. Part III: location of asthma inflammation and the distal airways: clinical implications. Curr Med Res Opin 2007;23(Suppl. 3):S21-7.

[16] Balzar S, Wenzel SE, Chu HW. Transbronchial biopsy as a tool to evaluate small airways in asthma. Eur Respir J 2002;20(2):254-9.

[17] Tashkin DP. The role of small airway inflammation in asthma. Allergy Asthma Proc 2002;23(4):233-42.

[18] Hamid QA. Peripheral inflammation is more important than central inflammation. Respir Med 1997:91(Suppl. A):11-2.

[19] Carroll NG, Mutavdzic S, James AL. Distribution and degranulation of airway mast cells in normal and asthmatic subjects. Eur Respir J 2002;19(5):879-85.

[20] Berry M, Hargadon B, Morgan A, Shelley M, Richter J, Shaw D, et al. Alveolar nitric oxide in adults with asthma: evidence of distal lung inflammation in refractory asthma. Eur Respir J 2005;25(6):986-91.

[21] Benayoun L, Druilhe A, Dombret MC, Aubier M, Pretolani M. Airway structural alterations selectively associated with severe asthma. Am J Respir Crit Care Med 2003;167(10):1360-8.

[22] Wenzel S. Severe asthma in adults. Am J Respir Crit Care Med 2005;172(2): 149-60. 
[23] Kraft M, Pak J, Martin RJ, Kaminsky D, Irvin CG. Distal lung dysfunction at night in nocturnal asthma. Am J Respir Crit Care Med 2001:163(7):1551-6.

[24] Kraft M, Martin RJ, Wilson S, Djukanovic R, Holgate ST. Lymphocyte and eosinophil influx into alveolar tissue in nocturnal asthma. Am J Respir Crit Care Med 1999;159(1):228-34.

[25] Irvin CG, Pak J, Martin RJ. Airway-parenchyma uncoupling in nocturnal asthma. Am J Respir Crit Care Med 2000;161(1):50-6.

[26] Enright PL, Lebowitz MD, Cockroft DW. Physiologic measures: pulmonary function tests. Asthma outcome. Am J Respir Crit Care Med 1994;149(2 Pt 2): S9-18. discussion S19-20.

[27] Ruppel GL, Enright PL. Pulmonary function testing. Respir Care 2012;57(1): $165-75$.

[28] Stănescu D. Small airways obstruction syndrome. Chest 1999;116(1):231-3.

[29] Halbert RJ, Natoli JL, Gano A, Badamgarav E, Buist AS, Mannino DM. Global burden of COPD: systematic review and meta-analysis. Eur Respir J 2006;28: 523-32.

[30] Timmins S, Diba C, Farrow C, Shoeffel R, Berend N, Salome C, et al. The relationship between airflow obstruction, emphysema extent and small airways function in COPD. Chest 2012;142(2):312-9.

[31] Pellegrino R, Viegi G, Brusasco V, Crapo RO, Burgos F, Casaburi R, et al Interpretative strategies for lung function tests. Eur Respir J 2005;26(5): 948-68.

[32] Sorkness RL, Bleecker ER, Busse WW, Calhoun WJ, Castro M, Chung KF, et al. Lung function in adults with stable but severe asthma: air trapping and incomplete reversal of obstruction with bronchodilation. J. Appl. Phys. 2008; 104:394-403.

[33] Dubois AB, Brody AW, Lewis DH, Burgess Jr BF . Oscillation mechanics of lungs and chest in man. J Appl Physiol 1956;8:587-94.

[34] Marotta A, Klinnert MD, Price MR, Larsen GL, Liu AH. J Allergy Clin Immunol 2003;112:317-22.

[35] Smith HJ, Reinhold P, Goldman MD. Forced oscillation technique and impulse oscillometry [Chapter 5]. In: Gosselink R, Stam H, editors. Lung function testing: European respiratory society monograph, vol. 31. Sheffield, UK: European Respiratory Society; 2005.

[36] Nève V, Edmé JL, Devos P, Deschildre A, Thumerelle C, Santos C, et al. Spirometry in 3-5-year-old children with asthma. Pediatr Pulmonol 2006 Aug:41(8):735-43.

[37] Takeda T, Oga T, Niimi A, Matsumoto H, Ito I, Yamaguchi M, et al. Relationship between small airway function and health status, dyspnea and disease control in asthma. Respiration 2010;80(2):120-6.

[38] Winkler J, Hagert-Winkler A, Wirtz H, Schauer J, Kahn T, Hoheisel G. Impulse oscillometry in the diagnosis of the severity of obstructive pulmonary disease. Pneumologie 2009;63(5):266-75.

[39] Oppenheimer BW, Goldring RM, Berger KI. Distal airway function assessed by oscillometry at varying respiratory rate: comparison with dynamic compliance. COPD 2009 Jun;6(3):162-70.

[40] Drummond GB, Milic-Emili J. Forty years of closing volume. Br J Anaesth 2007; 99(6):772-4.

[41] Buist AS. Current status of small airways disease. Chest 1984;86(1):100-5.

[42] van Veen IH, Sterk PJ, Schot R, Gauw SA, Rabe KF, Bel EH. Eur Respir J 2006 May;27(5):951-6.

[43] Dutrieue B, Vanholsbeeck F, Verbanck S, Paiva M. A human acinar structure for simulation of realistic alveolar plateau slopes. J Appl Physiol 2000;89(5): 1859-67.

[44] Verbanck S, Schuermans D, van Muylem A, Melot C, Noppen M, Vincken W, et al. Conductive and acinar lung-zone contributions to ventilation inhomogeneity in COPD. Am J Respir Crit Care Med 1998;157:1573-7.

[45] Verbanck S, Schuermans D, Paiva M, Vincken W. The functional benefit of anti-inflammatory aerosols in the lung periphery. J Allergy Clin Immunol 2006;118(2):340-6.

[46] Verbanck S, Schuermans D, Van Muylem A, Paiva M, Noppen M, Vincken W. Ventilation distribution during histamine provocation. J Appl Physiol 1997; 83(6):1907-16.

[47] Verbanck S, Thompson BR, Schuermans D, Kalsi H, Biddiscombe M, StuartAndrews $\mathrm{C}$, et al. Ventilation heterogeneity in the acinar and conductive zones of the normal ageing lung. Thorax 2012 Sep;67(9):789-95.

[48] Peslin R, Navajas D, Rotger M, Farré R. Validity of the esophageal balloon technique at high frequencies. J Appl Physiol 1993;74(3):1039-44.

[49] Ingram RH, Schilder DP. Association of decrease in dynamic compliance with a change in gas distribution. J Appl Physiol 1967;23:911.

[50] Fowler WS. Lung function studies. III. Uneven pulmonary ventilation in normal subjects and in patients with pulmonary disease. J Appl Physiol 1949; 2:283.

[51] Buist AS, Ross BB. Quantitative analysis of the alveolar plateau in the diagnosis of early obstruction. Am Rev Respir Dis 1973;108:1078.

[52] Barnes PJ, Dweik RA, Gelb AF, Gibson PG, George SC, Grasemann $\mathrm{H}$, et al. Exhaled nitric oxide in pulmonary diseases: a comprehensive review. Chest 2010;138(3):682-92.

[53] Stern G, de Jongste J, van der Valk R, Baraldi E, Carraro S, Thamrin C, et al. Fluctuation phenotyping based on daily fraction of exhaled nitric oxide values in asthmatic children. J Allergy Clin Immunol 2011;128(2):293-300.

[54] Horváth I, Hunt J, Barnes PJ, Alving K, Antczak A, Baraldi E, et al., ATS/ERS Task Force on Exhaled Breath Condensate. Exhaled breath condensate: methodological recommendations and unresolved questions. Eur Respir J 2005;26(3): 523-48.
[55] Battaglia S, den Hertog H, Timmers MC, Lazeroms SP, Vignola AM, Rabe KF, et al. Small airways function and molecular markers in exhaled air in mild asthma. Thorax 2005;60(8):639-44.

[56] Sofia M, Maniscalco M, de Laurentiis G, Paris D, Melck D, Motta A. Exploring airway diseases by NMR-based metabonomics: a review of application to exhaled breath condensate. J Biomed Biotechnol 2011:403260.

[57] Carraro S, Rezzi S, Reniero F, Héberger K, Giordano G, Zanconato S, et al. Metabolomics applied to exhaled breath condensate in childhood asthma. Am J Respir Crit Care Med 2007;175(10):986-90.

[58] Gono H, Fujimoto K, Kawakami S, Kubo K. Evaluation of airway wall thickness and air trapping by HRCT in asymptomatic asthma. Eur Respir J 2003;22:965-71.

[59] Laurent F, Latrabe V, Raherison C, Marthan R, Tunon-de-Lara JM. Functional significance of air trapping detected in moderate asthma. Eur Radiol 2000;10: $1404-10$.

[60] Newman KB, Lynch DA, Newman LS, Ellegood D, Newell Jr JD. Quantitative computed tomography detects air trapping due to asthma. Chest 1994;106: 105-9.

[61] Beigelman-Aubry C, Capderou A, Grenier PA, Straus C, Becquemin MH, Similowski T, et al. Mild intermittent asthma: CT assessment of bronchial cross-sectional area and lung attenuation at controlled lung volume. Radiology 2002;223:181-7.

[62] Goldin JG, Tashkin DP, Kleerup EC, Greaser LE, Haywood UM, Sayre JW, et al. Comparative effects of hydrofluoroalkane and chlorofluorocarbon beclomethasone dipropionate inhalation on small airways: assessment with functional helical thin-section computed tomography. J Allergy Clin Immunol 1999;104:S258-67.

[63] Jain N, Covar RA, Gleason MC, Newell Jr JD, Gelfand EW, Spahn JD. Quantitative computed tomography detects peripheral airway disease in asthmatic children. Pediatr Pulmonol 2005;40(3):211-8.

[64] Busacker A, Newell Jr JD, Keefe T, Hoffman EA, Granroth JC, Castro M, et al. A multivariate analysis of risk factors for the air-trapping asthmatic phenotype as measured by quantitative CT analysis. Chest 2009;135(1): 48-56.

[65] Tunon-de-Lara JM, Laurent F, Giraud V, Perez T, Aguilaniu B, Meziane H, et al. Air trapping in mild and moderate asthma: effect of inhaled corticosteroids. J Allergy Clin Immunol 2007;119:583-90.

[66] Montaudon $M$, Lederlin $M$, Reich S, Begueret $H$, Tunon-de-Lara JM, Marthan $\mathrm{R}$, et al. Bronchial measurements in patients with asthma: comparison of quantitative thin-section CT findings with those in healthy subjects and correlation with pathologic findings. Radiology 2009;253: 844-53.

[67] Chrystyn H, Price D. Not all asthma inhalers are the same: factors to consider when prescribing an inhaler. Prim Care Resp J 2009;18(4):243-9.

[68] Laube BL, Janssens HM, de Jongh FH, Devadason SG, Dhand R, Diot P, et al., European Respiratory Society; International Society for Aerosols in Medicine. What the pulmonary specialist should know about the new inhalation therapies. Eur Respir J 2011;37(6):1308-31.

[69] Fabbri LM, Nicolini G, Olivieri D, Papi A. Inhaled beclometasone dipropionate/formoterol extra-fine fixed combination in the treatment of asthma: evidence and future perspectives. Expert Opin Pharmacother 2008;9(3): 479-90.

[70] Nicolini G, Scichilone N, Bizzi A, Papi A, Fabbri LM. Beclomethasone/formoterol fixed combination for the management of asthma: patient considerations. Ther Clin Risk Manag 2008;4(5):855-64.

[71] Hauber H, Taha R, Bergeron C, Migounov V, Hamid Q, Olivenstein R. Effects of hydrofluoroalkane and dry powder-formulated corticosteroids on sputum inflammatory markers in asthmatic patients. Can Respir J 2006;13: $73-8$.

[72] Busse WW, Brazinsky S, Jacobson K, Stricker W, Schmitt K, Vanden Burgt J, et al. Efficacy response of inhaled beclomethasone dipropionate in asthma is proportional to dose and is improved by formulation with a new propellant J Allergy Clin Immunol 1999;104:1215-22.

[73] Juniper EF, Price DB, Stampone PA, Creemers JPHM, Mol SJM, Fireman P. Clinically important improvements in asthma-specific quality of life, but no difference in conventional clinical indexes in patients changed from conventional beclomethasone dipropionate to approximately half the dose of extrafine beclomethasone dipropionate. Chest 2002;121: 1824-32.

[74] Huchon G, Magnussen H, Chuchalin A, Dymek L, Gonod FB, Bousquet J. Lung function and asthma control with beclomethasone and formoterol in a single inhaler. Respir Med 2009;103:41-9.

[75] Papi A, Paggiaro P, Nicolini G, Vignola AM, Fabbri LM. Beclomethasone/formoterol vs fluticasone/salmeterol inhaled combination in moderate to severe asthma. Allergy 2007;62:1182-8.

[76] Papi A, Paggiaro PL, Nicolini G, Vignola AM, Fabbri LM. Beclomethasone/formoterol versus budesonide/formoterol combination therapy in asthma. Eur Respir J 2007;29:682-9.

[77] Müller V, Gálffy G, Eszes N, Losonczy G, Bizzi A, Nicolini G, et al. Asthma control in patients receiving inhaled corticosteroid and long-acting beta2agonist fixed combinations. A real-life study comparing dry powder inhalers and a pressurized metered dose inhaler extrafine formulation. BMC Pulm Med 2011;11:40.

[78] Allegra L, Cremonesi G, Girbino G, Ingrassia E, Marsico S, Nicolini G, et al., PRISMA (PRospectlve Study on asthMA control) Study Group. Real-life 
prospective study on asthma control in Italy: cross-sectional phase results. Respir Med 2012;106(2):205-14.

[79] Scichilone N, Battaglia S, Sorino C, Paglino G, Martino L, Paterno A, et al. Effects of extra-fine inhaled beclomethasone/formoterol on large and small airways in asthma. Allergy 2010;65(7):897-902.

[80] Leach CL, Kuehl PJ, Chand R, Ketai L, Norenberg JP, McDonald JD. Characterization of respiratory deposition of fluticasone-salmeterol hydrofluoroalkane134a and hydrofluoroalkane-134a beclomethasone in asthmatic patients. Ann Allergy Asthma Immunol 2012 Mar;108(3):195-200.
[81] Hozawa S, Terada M, Hozawa M. Comparison of budesonide/formoterol Turbuhaler with fluticasone/salmeterol Diskus for treatment effects on smal airway impairment and airway inflammation in patients with asthma. Pulm Pharmacol Ther 2011 Oct;24(5):571-6.

[82] De Backer W. Lung deposition of BDP/formoterol HFA pMDI in healthy volunteers, asthmatic, and COPD patients. J Aerosol Med Pulm Drug Deliv 2010 Jun;23(3):137-48.

[83] Kleinstreuer C, Zhang Z. Airflow and particle transport in the human respiratory system. Ann Rev Fluid Mechanics 2010;42:301-34 